flexibility between the different parts of the treatment modality, ensure provision of both a generalised and specialised programme working in parallel.

To combat the perpetuating factors involved in psychiatric illness, which in the majority of cases proved to be social isolation and unemployment, the resource groups, work placements and horticultural training programme have been of great value. They have also contributed to the low readmission rate. The on-going psychotherapy supervision available to staff ensures both quality care for patients and high morale for staff, both vital ingredients to successful community psychiatry.

Treating patients in the community over a 24-hour period highlights legal implications for staff and patients. The legal problem should be reviewed at a national level.

\section{Acknowledgement}

I would like to thank Dr P. O'Beirne, Chief Psychiatrist, Our Lady's Hospital, Ennis, and all the staff members at Kilrush Day Hospital for their valuable help in setting up the service.

\section{Reference}

GoldberG, D. \& HuXLeY, P. (1980) Mental Illness in the Community: the Pathway to Psychiatric Care. (Fig. 1, p. 11). London: Tavistock.

\title{
Conflict: not caring for people
}

\author{
Tony Whitehead, Consultant Psychiatrist with a Special Responsibility to the Elderly, \\ Brighton Health Authority
}

The publication Caring for People: Community Care in the Next Decade and Beyond (DoH, 1989) sets out the Government's plans for community care and is the much awaited response of Government to Sir Roy Griffiths' report on community care. Many health districts have been doing all, if not more, than is recommended in the White Paper but this has been rather costly as far as the DSS funding is concerned. It should be remembered that the high cost of community care to the DSS was one major reason for Sir Roy being asked to investigate and report on such care.

I think it might be worthwhile to look at what has been happening in my health district and then consider what effects the implementation of the White Paper will have upon our practice and the consequences for all districts.

\section{The Brighton service}

What is now Brighton Health District has had a special service for elderly people with mental illness since 1966. By 1987 the district was self sufficient, with a complex of services distributed between three units, each serving a specific sector.

From its inception the service was based on the principle of treating, helping and supporting elderly people in their own homes. It was accepted that inpatient care was sometimes necessary and that some individuals needed a protected environment for the rest of their lives. It was considered that the latter should be accommodated in small units within their communities. These units should be provided by the social services department and the health service with old people's homes and the health service nursing homes. But the NHS nursing homes never materialised and local authority social services homes were sometimes inappropriate to the needs of clients. Because of this, private and voluntary facilities were used.

Long-stay hospital facilities have been avoided because their quality tends to be poor and they are usually provided far from the patient's community. A survey of Health Advisory Service reports on 
psychiatric hospitals revealed a very grim picture of long-stay care. Particularly depressing was the deterioration of psychiatric hospitals which had previously been centres of excellence. However enthusiastic and humane staff were, something seemed to happen to drag them all back to the well documented descriptions of custodians of annexes to the mortuary.

The unit that serves Brighton Borough is highlighted because it has been self-sufficient for the past 11 years. It consists of two in-patient wards providing 34 places and two day hospitals providing 50 day places, plus one assessment and two continuing care clinics coordinated by a liaison charge nurse. The over 65 population served is 31,245 .

The in-patient wards and day hospitals have the usual complement of staff. There are three community psychiatric nurses, with other inpatient and day hospital nurses occasionally working in the community. There is one consultant psychiatrist, one senior house officer, two part-time medical assistants, one social worker and a parttime psychologist.

Patients requiring continuing care are placed in local authority old people's homes and nursing homes. These patients are followed up indefinitely since it is considered that the unit has a responsibility to them that it can either carry out itself or, if they move to another sector, pass to that sector's team after six months.

In line with its registration policy for private homes, East Sussex Social Services has upgraded its homes, abolishing multi-occupied rooms and improving the balance between single and double rooms. Inevitably these improvements have reduced the number of places available, while ward closures have reduced health authority places. The average annual referral rate to the unit is 250 . There are approximately 400 admissions each year with a majority being discharged home. Approximately 45 patients a year require residential continuing care. Of these, 11 go to local authority old people's homes, 17 to private or voluntary old people's homes and 17 to private nursing homes.

At present, the number of known patients in continuing care from the Brighton unit is 138, distributed as follows: 51 in local authority old people's homes, 54 in private or voluntary old people's homes and 33 in private or voluntary nursing homes. Using a pragmatic approach to continuing care of old people with mental illness, 70 to 85 individuals are supported in private and voluntary facilities at any one time.

This system has worked because Brighton has such a large number of private facilities, and because of the philosophy of the unit, which demands supervision of those who are placed in private establishments.
Unfortunately certain problems have already arisen. The unit's philosophy of placing individuals in establishments which charge within the DSS limits is threatened by the failure of the DSS to keep up with the increasing cost of care. This is illustrated by the following statistics.

In Brighton and Hove boroughs there are 145 private and voluntary old people's homes (five with elderly mentally infirm registration) and 50 private nursing homes (six with psychiatric registration). The proportion of places in rest homes at DSS levels varies, but experience suggests it is less than $40 \%$; single rooms are rarely available and many include the personal allowance as part of the fees.

Less than $30 \%$ of nursing home places are available at DSS rates, many including the personal allowance as part of the fee. For people with psychiatric disorders this percentage could be less than $10 \%$.

\section{The Community Care White Paper}

The White Paper consists of eleven chapters plus tables and charts which make up 106 pages. It contains a lot of good ideas but these are very dependent upon adequate funding and few will believe that there will be adequate funding. Of particular signifcance in this respect is the idea that local authorities will hold the budget for community care and, while being allowed to provide some of the necessary services themselves, it is fairly strongly suggested that these services should, and would, be provided by the commercial and voluntary sectors. It is also recommended that health authorities maintain a limited amount of continuing care facilities which would be used for those individuals who need a significant degree of medical, nursing and other Health Service facilities. It is also made clear that funding for community care will not be ring-fenced. When these recommendations are considered it can be seen that a number of problems will arise and consequently conflict generated.

In the past there were varying degrees of conflict between Health and Social Services over the accommodation of individuals who require long-stay care. Units for the elderly mentally ill tended to be overcrowded and when patients were recommended for care in local authority old people's homes, it was commonplace to have these requests rejected on various grounds. This was not because the Social Services' workers were being difficult or awkward but because they, in turn, had limited resources and preferred to keep these resources for people who were actually in the community. Developments over the past ten or more years have reduced these conflicts considerably and in some areas, such as Brighton Health District, they no longer occur. Implementation of the White Paper will bring all this back 
again. A local authority with a limited budget will find difficulties in financing individuals who need continuing care and hence it is likely that a number of games will be played. The following are a few scenarios:

An elderly lady living alone develops a dementing illness and is supported in her own home by providing the usual community support, plus attendance at a Health Service day hospital. Time passes and her disabilities increase. The time comes when she can no longer be supported in her own home and it is suggested that she enters either a rest home or possibly a nursing home. An application is made to the local authority for such a placement but at the time of year that this occurs the budget is already overspent. The response from the Social Services Department will be to the effect that the lady now requires the special care that only a hospital can provide. The hospital has a reasonable number of acute beds for the elderly mentally ill but only a very small number of long-stay beds. These, of course, are full.

An elderly gentleman is admitted to a unit for the elderly mentally ill because of severe depression. This is successfully treated but he is found to have a dementing illness. Prior to his admission he was living in a hostel and the hostel will not accept him back because of his dementia. It could be that if he had a home he could be supported there but there is no home and it is suggested that he be accommodated in an old people's home. An application is made to the local authority but again the funding is running out and they claim that he is now well settled in the hospital, enjoys the hospital environment and would be best transferred to the hospital's non-existent long-stay facilities; non-existent, in this case, because the health authority had decided not to have any long-stay facilities.

An elderly lady living in the community is discovered to be severely demented and failing to cope. Up to this time there has been no input because nobody was aware of her problems and the conditions under which she lives. She is carefully assessed by a psychogeriatric team and it is decided that her problems are purely those of Alzheimer's disease. It is recommended that she enters an EMI rest home. There is little money available and the Social Services Department suggests that she should be admitted to hospital for a fuller assessment, following which her future can be re-examined. After a period in hospital it is quite clear that the original assessment was correct and once again an application is made for her to be accommodated in an EMI registered old people's home. There is still no money available and the Social Services Department recommends that she should go to a long-stay facility within the hospital.

I am sure the official response will be that none of these things will happen because modern management will ensure that money is not wasted and, as a consequence, it will be available for individuals like the ones mentioned who are in need of specific types of support. Experience suggests that changes in management have not improved the Health Service in general and the care of the elderly and psychiatrically ill in particular. This is not because the managers are bad, incompetent, lazy or anything else. It is because the Health Service and local authority Social Services Departments are grossly underfunded. The White Paper is not going to solve the underfunding and, I suspect, is going to make it worse. Miraculous management could solve these problems but miracles are hard to come by.

\section{Comment}

A survey of the Brighton experience with the elderly mentally ill suggests that the present cost for residential continuing care in a third of the district is approximately $£ 17,000$ per week and $£ 884,000$ per year. Within Brighton Health District considerable efforts have been made over the years to ensure that individuals are maintained in their own homes for as long as it is possible. Every effort is made to establish packages of care to ensure this happens. In spite of this, a significant number of individuals do require continuing care and this is provided in old people's homes and nursing homes. The White Paper advocates the same policy but places the financing of community care in the hands of local authority Social Services Departments. With adequate funding this could be a success but, without it, the result could be catastrophic with individuals not receiving the help and support they require, families damaged by having to pay for facilities which they can ill afford and conflict being generated between Health and Social Services when conflict was becoming a thing of the past.

It could be argued that what we have at present is very satisfactory and could be made better by a moderate increase in funding. The White Paper's recommendations at their best will not make anything better in districts where the problem of the elderly and the mentally ill have been faced and dealt with. At worst, they will make little difference to underdeveloped districts and destroy what has been achieved in many progressive districts.

\section{Reference}

Department of Health (1989) Caring for People: Community Care in the Next Decade and Beyond. Cmnd 849. London: HMSO. 